\title{
A Nanoarchitecture Based on Silver and Copper Oxide with an Exceptional Response in the Chlorine-Promoted Epoxidation of Ethylene
}

\author{
Adrian Ramirez, Jose L. Hueso, * Hugo Suarez, Reyes Mallada, Alfonso Ibarra, Silvia Irusta, and \\ Jesus Santamaria*
}

\begin{abstract}
Title reworded slightly for clarity: silver-copper oxide could be confused for (silver oxide)/(copper oxide). We also avoid words like "new" or "novel" in titles. $\square$ The selective oxidation of ethylene to ethylene epoxide is highly challenging as a result of competing reaction pathways leading to the deep oxidation of both ethylene and ethylene oxide. Herein we present a novel catalyst based on silver and copper oxide with an excellent response in the selective oxidation pathway towards ethylene epoxide. The catalyst is composed of different silver nanostructures dispersed on a tubular copper oxide matrix. This type of hybrid nanoarchitecture seems to facilitate the accommodation of chlorine promoters, leading to high yields at low reaction temperatures. The stability after the addition of chlorine promoters implies a substantial improvement over the industrial practice: a single pretreatment step at ambient pressure suffices in contrast with the common practice of continuously feeding organochlorinated precursors during the reaction.
\end{abstract}

$E_{\mathrm{t}}$ paramount importance in the chemical industry for the production of multiple oxygenated end-products. ${ }^{[1]}$ The main goal in EO production processes is to increase the selectivity and the EO concentration at the outlet of the reactor. However, maintaining a high selectivity at moderate to high conversion rates remains challenging in view of the susceptibility of ethylene and EO to be completely oxidized to $\mathrm{CO}_{2}$ in the presence of oxygen. ${ }^{[2]}$

[*] A. Ramirez, Dr. J. L. Hueso, H. Suarez, Dr. R. Mallada, Dr. S. Irusta, Prof. J. Santamaria

Department of Chemical Engineering and Environmental Technology and Institute of Nanoscience of Aragon (INA)

University of Zaragoza

50018 Zaragoza (Spain)

E-mail: jlhueso@unizar.es jesus.santamaria@unizar.es

Dr. J. L. Hueso, Dr. R. Mallada, Dr. S. Irusta, Prof. J. Santamaria Networking Research Centre on Bioengineering, Biomaterials, and Nanomedicine CIBER-BBN

28029 Madrid (Spain)

Dr. A. Ibarra

Advanced Microscopy Laboratory and Institute of Nanoscience of Aragon (LMA-INA), University of Zaragoza

50018 Zaragoza (Spain)

(64) Supporting information and the ORCID identification number(s) for 1002/anie.201603886
The reference industrial catalysts for this reaction consist of large silver nanoparticles (100-200 nm) supported (circa $15 \%$ wt.) on low-surface-area alumina. Over the years, these catalysts have been highly optimized by promotion with alkali metals (mainly cesium) ${ }^{[3]}$ and also with other metals, such as rhenium, molybdenum, tungsten, and chromium. ${ }^{[4,5]}$ To minimize the formation of $\mathrm{CO}_{2}$, chlorine-containing compounds, such as 1,2-dichloroethane (DCE), hydrochloric acid, and ethyl chloride, are also used as promoters. ${ }^{[6,7]}$ These chlorinated compounds are added continuously to the reactor feed and have a strong influence on the final EO selectivity. Furthermore, it is also customary typical? Common? to add ethane to the reactor feed (around 10\% of the total volume) to facilitate the adsorption/desorption equilibrium of $\mathrm{Cl}$ on the $\mathrm{Ag}$ surface. Otherwise irreversible poisoning of the $\mathrm{Ag}$ active sites by $\mathrm{Cl}$ occurs. ${ }^{[3,7]}$

Due to the industrial importance of this reaction, many efforts have been devoted to the design of a catalyst that could outperform the silver-alumina system. Barteau et al. showed both theoretically ${ }^{[8]}$ and experimentally ${ }^{[3,9]}$ that copper-silver bimetallic catalysts increase the performance of conventional $\mathrm{Ag}$ catalysts, achieving higher selectivity towards EO. Other reports aiming at a rational design of catalytic surfaces suggest that the presence of $\mathrm{Cu}$ on the surface of the catalyst could critically affect the epoxidation mechanism. ${ }^{[8,10-12]} \mathrm{Cu}$ tends to oxidize at the reaction temperatures forming $\mathrm{CuO}$ surfaces alongside the $\mathrm{Ag}$ particles and, depending on the catalyst surface structure, this combination of silver and copper oxide can increase the selectivity towards EO ${ }^{[11,13]}$ Another important fact regarding the specific role of $\mathrm{Cu}$ is that both $\mathrm{Cu}$ and $\mathrm{CuO}$ can interact with $\mathrm{Cl}$, in a similar way to how $\mathrm{Ag}$ does, with the already mentioned benefits regarding EO selectivity. ${ }^{[14-16]}$

Considering the above premises, herein we present a novel structure for a $\mathrm{Ag} / \mathrm{CuO}$ catalyst with a high content of both metals. This material can be prepared by a facile coprecipitation method (see the Experimental Section in Supporting Information), followed by a careful thermal treatment. Unlike other structures that are prepared by similar methods (for example the $\mathrm{Ag}_{2} \mathrm{Cu}_{2} \mathrm{O}_{3}$ material reported by Tejada-Rosales et al. ${ }^{[17]}$ that is inactive for ethylene epoxidation), we have obtained $\mathrm{Ag} / \mathrm{CuO}$ nanoarchitectures with highly accessible Ag nanoparticles and where the $\mathrm{Ag}$ and $\mathrm{CuO}$ are intimately linked, leading to an increase in the activity and the selectivity to EO.

A first examination of the morphology of the catalyst by using scanning electron microscopy (SEM) revealed a tubular 
configuration with a high aspect ratio with lengths of up to $1 \mu \mathrm{m}$ and variable widths between $30-200 \mathrm{~nm}$ (see Figure S1 in Supporting Information). Energy-dispersive X-ray spectroscopy (EDX) analysis at different spots showed a homogeneous overall chemical composition with $\mathrm{Ag}: \mathrm{Cu}$ atomic ratios of 0.97 (57\% wt. Ag in the solid), in agreement with the equimolar ratio of the initial solution (see the Experimental Section and Figure S1 in the Supporting Information). X-ray diffraction (XRD) and HR-TEM analysis confirmed the presence of two crystallographic phases assigned to metallic $\mathrm{Ag}(F m 3 m$ cubic $\square$ do you mean $F m \overline{3} m$ ? $\square)$ and $\mathrm{CuO}$ (C2/c monoclinic), respectively (Figures S2, S4, S5). To gain further insight into the distribution of the $\mathrm{Ag}$ nanostructures in relation to the $\mathrm{CuO}$ phases, high-angle annular dark field scanning transmission electron microscopy (HAADF-STEM) images were acquired, including a tomographic analysis carried out by taking up to 140 STEM images at varying angles from -70 to $70^{\circ}$ and reconstructing a three-dimensional model of a single $\mathrm{Ag} / \mathrm{CuO}$ tube. Different morphologies ranging from small nanoclusters to anisotropic rods accounted for the heterogeneous variety of shapes displaced in this $\mathrm{Ag} / \mathrm{CuO}$ catalyst (Figure $1 \mathrm{a}$; Figures S3-S5). The energy-dispersive (EDX) mapping analysis of the different layers of material compositions suggested a core-shell distribution with an irregular $\mathrm{Ag}$ core (outlined in red in Figure $1 \mathrm{~b}, \mathrm{c}$ ) in conjunction with multiple segregations $\square$ clusters? of $\mathrm{Ag}$ nanoparticles of a few nanometers in size
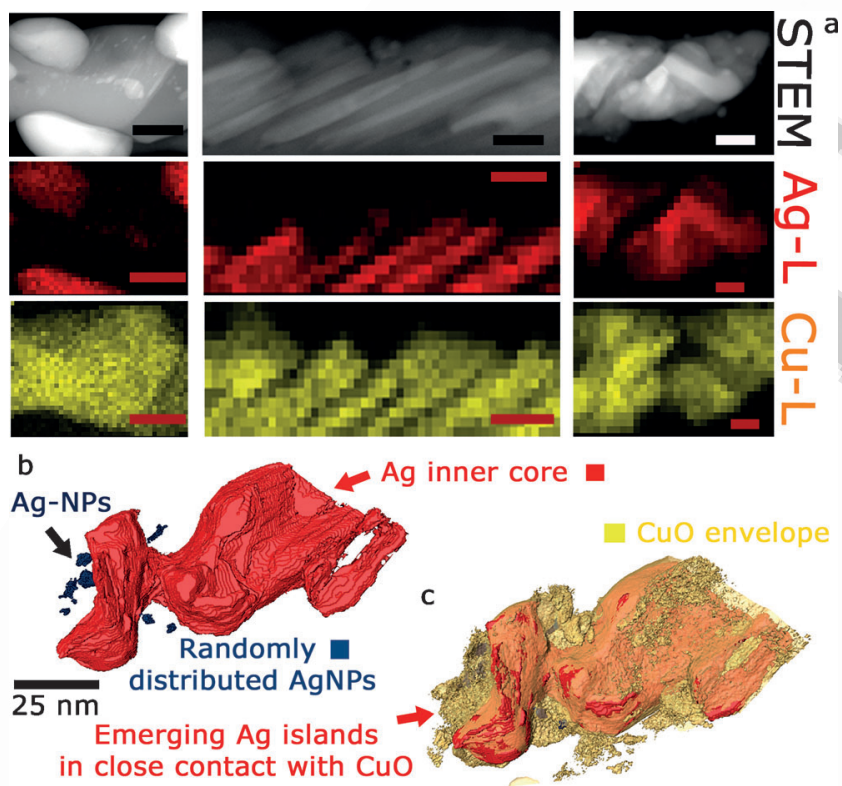

Figure 1. Morphochemical analysis of the $\mathrm{Ag} / \mathrm{CuO}$ catalyst: a) Selection of representative HAADF-STEM images and the corresponding EDX mapping analyses to determine the chemical distribution of $\mathrm{Ag}$ (red) and Cu (yellow) on the catalyst; b) Snapshot of the Ag fraction in a HAADF-STEM 3D tomography reconstruction of a $\mathrm{Ag} / \mathrm{CuO}$ nanotube: the red figure corresponds to the bulk $\mathrm{Ag}$ inner core while the blue dotted images are randomly distributed individual Ag NPs; c) Equivalent side-view reconstruction now including the $\mathrm{CuO}$ envelope (yellow color) covering the $\mathrm{Ag}$ core. The presence of $\mathrm{Ag} / \mathrm{CuO}$ intertwined areas with $\mathrm{Ag}$ islands emerging on the surface can be detected. All scale bars $=25 \mathrm{~nm}$.
(Figure 1b, AgNPs shown in blue). A $\mathrm{CuO}$ outer shell surrounds these $\mathrm{Ag}$ nanostructures (highlighted in yellow/ orange in Figure 1c; see also Figure S6 and the Movie in the Supporting Information) but interestingly, does not completely covering them. In summary, from the above observations, and especially from the 3D tomographic reconstruction, a picture emerges of a complex hybrid nanostructure in which metallic $\mathrm{Ag}$ and $\mathrm{CuO}$ are segregated but intertwined, with a high amount of shared interface area that facilitates interaction, and where a representative fraction of the $\mathrm{Ag}$ remains accessible to gas-phase reactants.

The evaluation of the catalytic activity of the $\mathrm{Ag} / \mathrm{CuO}$ hybrid catalyst for ethylene epoxidation was first carried out in the absence of promoters and compared with a reference silver-based catalyst (20\% wt. Ag) supported on $\alpha$-alumina and prepared by a conventional wetness impregnation method (Figure S7). The performance of this catalyst is similar to other unpromoted $\mathrm{Ag} / \mathrm{Al}_{2} \mathrm{O}_{3}$ catalysts in the literature (see for instance Ref. [9]). The results obtained during reaction under identical experimental conditions of both solids (that is, the $\mathrm{Ag} / \mathrm{Al}_{2} \mathrm{O}_{3}$ reference catalyst and the $\mathrm{Ag} / \mathrm{CuO}$ system)? are summarized in Table S1. It can be observed that the $\mathrm{Ag} / \mathrm{CuO}$ nanostructure greatly outperforms the reference $\mathrm{Ag} / \mathrm{Al}_{2} \mathrm{O}_{3}$ catalyst. At $225^{\circ} \mathrm{C}$, the conversion obtained with the $\mathrm{Ag} / \mathrm{CuO}$ catalyst is more than 20 times higher, but the reaction rate, referred to the mass of $\mathrm{Ag}$, is more than 40 times higher. Furthermore, with the $\mathrm{Ag} / \mathrm{CuO}$ catalyst, selectivity values are generally over 10 points higher at equivalent conversions and $21 \%$ yields can be achieved at only $225^{\circ} \mathrm{C}$. Furthermore, the $\mathrm{Ag} / \mathrm{CuO}$ structure starts to be active at a much lower temperature and $100^{\circ} \mathrm{C}$ is sufficient to obtain measurable conversions, instead of the $175^{\circ} \mathrm{C}$ typically reported for this reaction. ${ }^{[18]}$

As can be inferred from the preceding discussion, we credit the enhanced performance of the $\mathrm{Ag} / \mathrm{CuO}$ catalyst to the strong interplay between both phases, with a high degree of entanglement shown through electron microscopy images. The presence of $\mathrm{Cu}$ can withdraw electrons from nearby $\mathrm{Ag}$ atoms and rendering the $\mathrm{Ag}$ more electropositive, thereby increasing the electrophilicity of adsorbed oxygen species that favor the direct formation of EO. ${ }^{[19]}$

Perhaps the most compelling evidence regarding the singular nature of the $\mathrm{Ag} / \mathrm{CuO}$ catalyst compared to standard epoxidation catalysts can be obtained from the different behavior against poisoning by chlorine-containing compounds. To study this, we challenged both $\mathrm{Ag} / \mathrm{CuO}$ and $\mathrm{Ag} /$ $\mathrm{Al}_{2} \mathrm{O}_{3}$ reference catalysts by co-feeding of a $\mathrm{Cl}$ precursor $(1,2-$ dichloroethane, DCE) during the ethylene epoxidation reaction in the absence of ethane (ethane is generally added in industrial practice to counterbalance the poisoning effect of Cl) ${ }^{[3,20]}$ Their behavior was remarkably different, as shown in Figure 2, where the evolution of the rates of formation of $\mathrm{EO}$ and $\mathrm{CO}_{2}$ during the ethylene epoxidation reaction at $200^{\circ} \mathrm{C}$ is shown.

As expected, in the absence of ethane in the feed, the $\mathrm{Ag} /$ $\mathrm{Al}_{2} \mathrm{O}_{3}$ catalyst is quickly poisoned. After $30 \mathrm{~min}$, the reaction rate is one tenth of the initial, and becomes negligible after $2 \mathrm{~h}$ on stream (Figure $2 \mathrm{~b}$ ). In contrast, for the $\mathrm{Ag} / \mathrm{CuO}$ catalyst the EO formation rate initially increases, reaching a maximum 

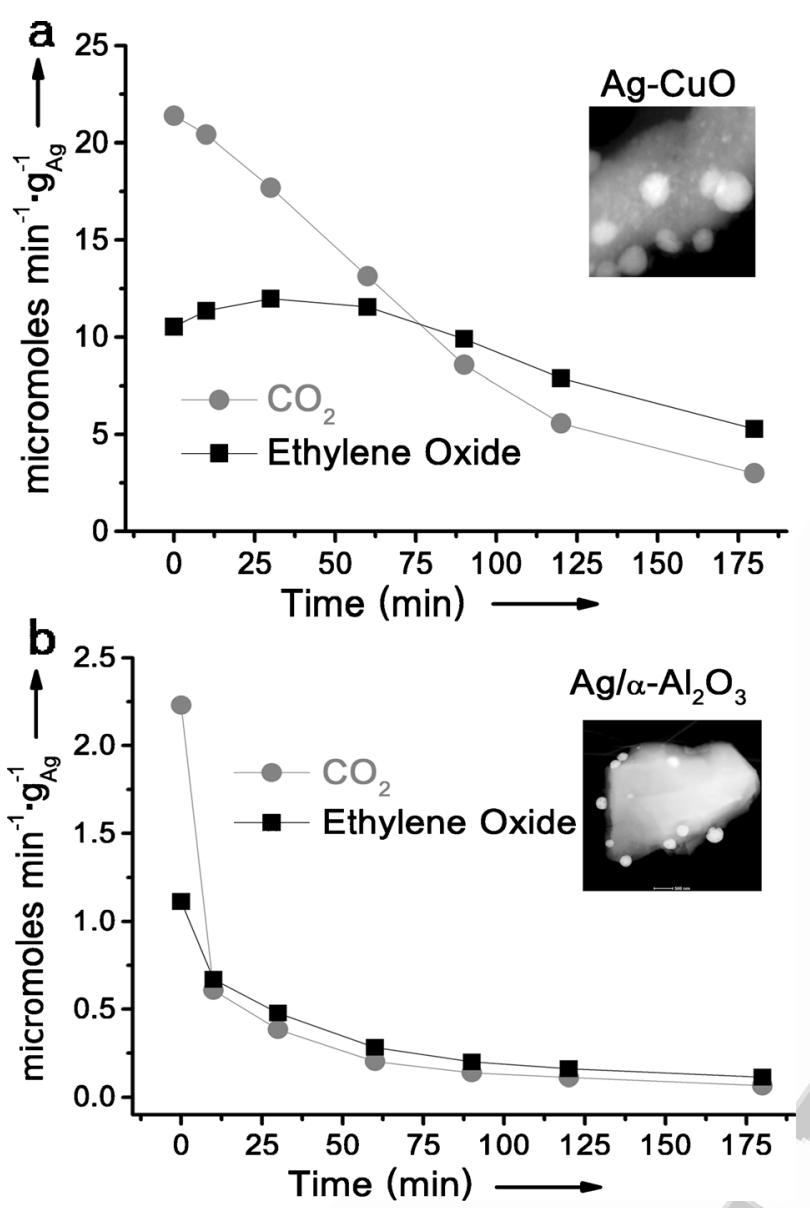

Figure 2. Evolution of the reaction rates of $\mathrm{CO}_{2}$ and $\mathrm{EO}$ during pretreatment with 1.2-dichloroethane (4 ppm) of the a) $\mathrm{Ag} / \mathrm{CuO}$ catalyst or the b) $\mathrm{Ag} / \mathrm{Al}_{2} \mathrm{O}_{3}$ catalyst. Temperature $=200^{\circ} \mathrm{C}$. The inlet flow contains $6 \%$ ethylene, $12 \%$ oxygen, and $88 \%$ helium. Insets: STEMHAADF images of the catalysts (see also the Supporting Information).

after about $40 \mathrm{~min}$ of poisoning and smoothly decreasing thereafter (Figure $2 \mathrm{a}$ ). Interestingly, for the $\mathrm{Ag} / \mathrm{CuO}$ catalyst the effects of $\mathrm{Cl}$ pretreatment are permanent, and depend solely on the total amount of DCE fed to the reactor. If at any time during pretreatment the DCE feed is stopped, the catalyst remains thereafter "frozen" in that state, with constant conversion and selectivity (Figure S8), independent of the amount of $\mathrm{Cl}$ previously dosed. Moreover, the catalyst maintains a stable performance for at least $40 \mathrm{~h}$ of operation at $200^{\circ} \mathrm{C}$, indicating that the $\mathrm{Cl}$ species irreversibly remain on the surface during reaction (Figure S9). This could be expected, since it has been reported that temperatures above $400^{\circ} \mathrm{C}$ are needed to remove the $\mathrm{Cl}$ from $\mathrm{Ag}^{[21]}$ and Cu surfaces.$^{[15]}$ Therefore, the presence of copper oxide seems to be playing a determinant role in the stabilization of chlorine atoms. This unique behavior means that chlorine promotion could be carried out only during the preparation of the catalysts, without the need to add DCE during reaction, with the economic and environmental advantages that this implies.

X-ray photoelectron spectroscopy (XPS) was used to confirm the presence of $\mathrm{Cl}$ on the catalyst surface and to evaluate the extent of penetration of $\mathrm{Cl}$ species into the $\mathrm{Ag} /$ $\mathrm{CuO}$ catalyst (Figure S10 and S11). Increasing the pretreatment time led to a deeper penetration of $\mathrm{Cl}$ species and after 1200 seconds of etching, $\mathrm{Cl}$ was only found for the catalyst pretreated for $3 \mathrm{~h}$.

The effect of $\mathrm{Cl}$ addition during ethylene epoxidation has been intensely studied. A widely supported idea states proposes? that $\mathrm{Cl}$ promotion decreases the energy barrier from the oxometallacycle intermediate (OMC) to EO relative to the nonselective pathway. ${ }^{[22,23]}$ Moreover, $\mathrm{Cl}$ species block oxygen vacancies on the $\mathrm{Ag}$ surface, thus preventing the formation of $\mathrm{OMC}$, which is deemed mainly is considered primarily? responsible for the nonselective reaction ${ }^{[2,23]}$ and favors the selective direct epoxidation route. Recently, Rocha et al ${ }^{[24]}$ demonstrated by in situ XPS analysis that $\mathrm{Cl}$ has a direct effect on oxygen atoms on the Ag surface, increasing the electrophilic nature of the oxygen adsorbed on Ag. In accordance with the direct epoxidation mechanism, ${ }^{[25]}$ an overall increase of the EO selectivity was detected. The interaction of $\mathrm{Cl}$ with $\mathrm{Ag}$ depends on the degree of coverage, ranging from an initial chemisorption at low coverage to the consolidation of segregated $\mathrm{AgCl}$ phases at higher coverage levels. ${ }^{[21]}$ The interaction with $\mathrm{Cu}$ or $\mathrm{CuO}$ is analogous but requires a lower number of intermediates to accommodate $\mathrm{Cl}$ atoms and forms $\mathrm{CuCl}$ or $\mathrm{CuCl}_{2}$ regardless of the amount of $\mathrm{Cl}$ added. ${ }^{[15]}$ Furthermore, the diffusion rates of the $\mathrm{Cl}$ atoms into $\mathrm{Ag}$ films are substantially lower than in $\mathrm{Cu}$ films. ${ }^{[14]} \mathrm{In}$ summary, $\mathrm{Cl}$ promotion appears to increase the electrophilicity of absorbed oxygen by electrostatic effects and is likely to be enhanced in the presence of $\mathrm{Cu}$ since copper chlorination occurs more readily than silver chlorination.

Considering our experimental observations, the reported studies of $\mathrm{Cl}$ promotion on $\mathrm{Ag}$ catalysts, and the interactions of $\mathrm{Ag}$ and $\mathrm{CuO}$ with $\mathrm{Cl}$, we suggest a chlorination mechanism

for? our catalyst, schematized in Figure $3 \mathrm{a}$. Two different outcomes are possible, depending on the $\mathrm{Cl}$ amount dosed, which in turn depends on the $\mathrm{Cl}$ concentration and contact time. For low DCE amounts, Cl-containing species will interact preferably with the $\mathrm{CuO}$, forming $\mathrm{CuO} / \mathrm{Cl}$ derivatives and acting as a chlorine sponge. $\square$ Ok? $\mathbf{\square}$ Thanks to the $\mathrm{Ag} / \mathrm{CuO}$ intertwined structure of our catalyst, these $\mathrm{Cl}$ atoms will increase the electrophilicity of the oxygen adsorbed on neighboring Ag surfaces while avoiding most of the poisoning effect. This is consistent with the observations in Figure $2 \mathrm{a}$, where, at lower pretreatment times $(<60 \mathrm{~min})$, the rate of formation of EO slightly increases as a consequence of the increase in the selectivity to EO that offsets the decrease in conversion. On the other hand, for higher doses of $\mathrm{Cl}$ precursors (contact times greater than $60 \mathrm{~min}$, see Figure $2 \mathrm{a}$ ), $\mathrm{Cl}$ interaction with $\mathrm{Ag}$ nanoparticles becomes more important, ultimately leading to poisoning of the catalyst. In this scenario, the selectivity continues to increase as $\mathrm{Cl}$ withdraws electrons from the adsorbed oxygen, but now $\mathrm{Cl}$ also blocks the vacancies available on $\mathrm{Ag}$, reducing the $\mathrm{EO}$ produced.

The performance of the $\mathrm{Ag} / \mathrm{CuO}$ catalyst with a pretreatment of $4 \mathrm{ppm}$ of $\mathrm{Cl}$ for $180 \mathrm{~min}$ is compared in Figure $3 \mathrm{~b}$ with some of the best reported results ${ }^{[3,20,26,27]}$ measured under similar experimental conditions (ethylene concentration (6$15 \%), \mathrm{C}_{2} \mathrm{H}_{4} / \mathrm{O}_{2}$ ratios varying from 1 to 2 , with and without 

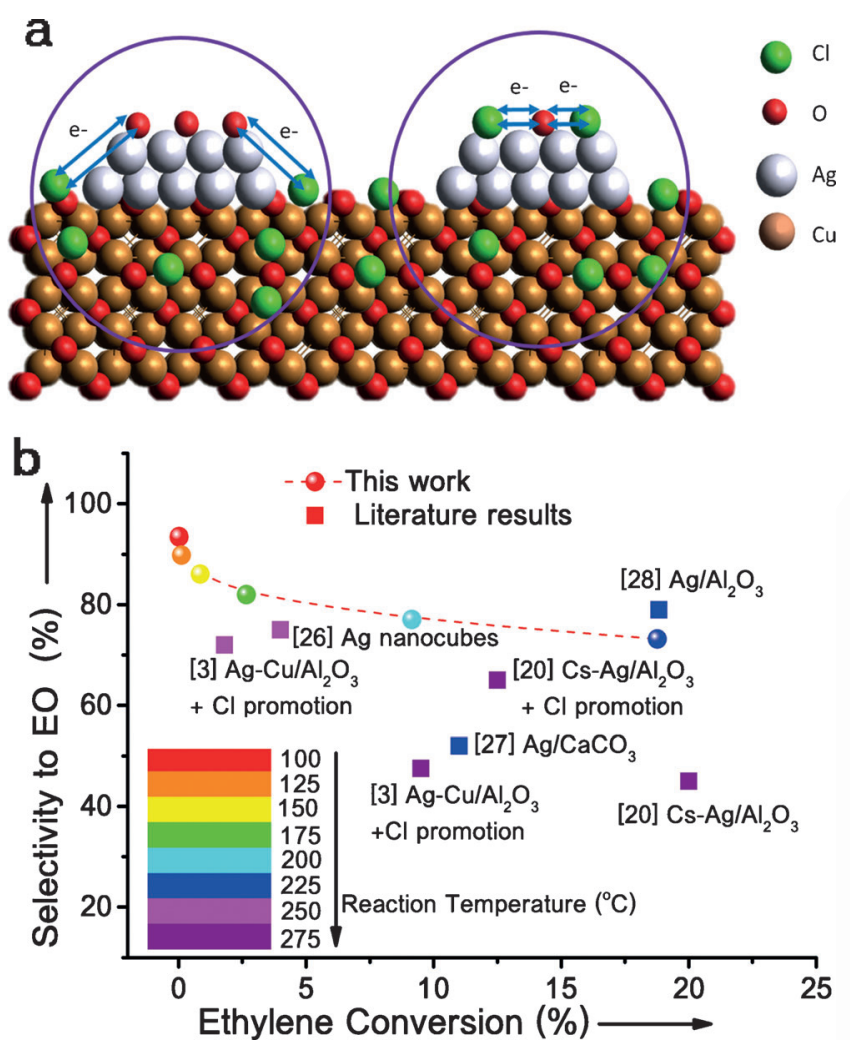

Figure 3. a) Representation of the proposed $\mathrm{Cl}$ promotion mechanism; the $\mathrm{Cl}$ atoms are readily adsorbed or substituted on both $\mathrm{CuO}$ and $\mathrm{Ag}$ surfaces and promote the generation of more electrophilic oxygen species in the vicinity; b) Overview of the best reported catalytic performances for ethylene epoxidation expressed in terms of selectivity to EO formation against total ethylene conversion. The $\mathrm{Ag} / \mathrm{CuO}$ catalyst pretreated with 4 ppm of 1,2-dichloroethane for $180 \mathrm{~min}$ (circle symbols) is selected for comparison. Results for previously reported systems are shown as square symbols. The different colors of circles and squares indicate different reaction temperatures (see inset legend). Numbers in square brackets indicate the reference in which the indicated system is reported. $\square$ Caption ok? Expanded to aid the reader.

promoters, at 1 bar of total pressure). In general, the selectivity to $\mathrm{EO}$ with the $\mathrm{Ag} / \mathrm{CuO}$ catalyst presented in this work is higher and the temperatures required to reach a certain conversion are considerably lower (circa $75^{\circ} \mathrm{C}$ lower), even when comparing with $\mathrm{Cs}$ or $\mathrm{Cs}+\mathrm{Cl}$ promoted catalysts $^{[20]}$ or when using lower oxygen concentrations (Figure $\mathrm{S} 12$ ). Only the recent results reported by Li et al. ${ }^{[28]}$ who prepared $\mathrm{Ag} / \alpha-\mathrm{Al}_{2} \mathrm{O}_{3}$ by an impregnation-bioreduction process with Cinnamomum camphora extract match the performance of the $\mathrm{Ag} / \mathrm{CuO}$ catalyst, although it is important to note that they were obtained under reaction at 20 bars of total pressure and at lower space velocity.

The fact that results comparable or better than the best reported in the open literature have been obtained with a simple and robust catalyst strongly suggests that $\mathrm{Ag} / \mathrm{CuO}$ catalysts may be a key platform for increasing the performance efficiency? of the ethylene epoxidation reaction in the near future. The high stability of the $\mathrm{Cl}$ promotion allows us to tune the catalytic performance simply by controlling the total dose of DCE supplied in the pretreatment step. This allows a simpler and more economical operation compared to standard practice with conventional catalysts, since the feeding of both ethane and chlorine-containing compounds during operation can be avoided.

\section{Acknowledgements}

Financial support from the European Research Council ERC-Advanced Grant HECTOR (project number 267626) is gratefully acknowledged.

Keywords: copper - epoxidation - ethylene oxide . heterogeneous catalysis · silver

[1] "Ethylene Oxide": S. Rebsdat, D. Mayer in Ullmann's Encyclopedia of Industrial Chemistry, Wiley-VCH, Weinheim, 2004.

[2] M. O. Özbek, R. A. van Santen, Catal. Lett. 2013, 143, 131-141.

[3] J. T. Jankowiak, M. A. Barteau, J. Catal. 2005, 236, 379-386.

[4] M. Matusz, M. A. Richard, M. L. Hess, Vol. US 20040198992 A1, Shel-C, 2004

[5] J. C. Dellamorte, J. Lauterbach, M. A. Barteau, Catal. Today 2007, 120, 182-185.

[6] C. T. Campbell, J. Catal. 1986, 99, 28-38.

[7] K. L. Yeung, A. Gavriilidis, A. Varma, M. M. Bhasin, J. Catal. 1998, 174, 1-12.

[8] S. Linic, J. Jankowiak, M. A. Barteau, J. Catal. 2004, 224, 489493.

[9] J. T. Jankowiak, M. A. Barteau, J. Catal. 2005, 236, 366-378.

[10] S. Piccinin, N. L. Nguyen, C. Stampfl, M. Scheffler, J. Mater. Chem. 2010, 20, $10521-10527$.

[11] N. L. Nguyen, S. de Gironcoli, S. Piccinin, J. Chem. Phys. 2013, 138,184707

[12] A. Kokalj, P. Gava, S. de Gironcoli, S. Baroni, J. Catal. 2008, 254, 304-309.

[13] S. Piccinin, S. Zafeiratos, C. Stampfl, T. W. Hansen, M. Havecker, D. Teschner, V. I. Bukhtiyarov, F. Girgsdies, A. Knop-Gericke, R. Schlogl, M. Scheffler, Phys. Rev. Lett. 2010, 104, 035503

[14] J. Poznanski, J. Less-Common Met. 1991, 169, 181-186.

[15] G. De Micco, A. E. Bohe, D. M. Pasquevich, J. Alloys Compd. 2007, 437, 351-359.

[16] I. A. Suleiman, M. W. Radny, M. J. Gladys, P. V. Smith, J. C. Mackie, E. M. Kennedy, B. Z. Dlugogorski, Phys. Chem. Chem. Phys. 2011, 13, 10306-10311

[17] E. M. Tejada-Rosales, J. Rodriguez-Carvajal, N. Casan-Pastor, P. Alemany, E. Ruiz, M. S. El-Fallah, S. Alvarez, P. GomezRomero, Inorg. Chem. 2002, 41, 6604-6613.

[18] A. P. Fotopoulos, K. S. Triantafyllidis, Catal. Today 2007, 127, $148-156$.

[19] W. J. Diao, C. D. DiGiulio, M. T. Schaal, S. G. Ma, J. R. Monnier, J. Catal. 2015, 322, 14-23.

[20] D. Lafarga, A. Varma, Chem. Eng. Sci. 2000, 55, 749-758.

[21] M. Bowker, K. C. Waugh, B. Wolfindale, G. Lamble, D. A. King, Surf. Sci. 1987, 179, 254-266.

[22] D. Torres, F. Illas, R. M. Lambert, J. Catal. 2008, 260, 380-383.

[23] M. O. Ozbek, I. Onal, R. A. Van Santen, J. Phys. Condens. Matter 2011, 23, 404202.

[24] T. C. R. Rocha, M. Havecker, A. Knop-Gericke, R. Schlogl, J. Catal. 2014, 312, $12-16$. 
[25] V. V. Kaichev, V. I. Bukhtiyarov, M. Havecker, A. Knop-Gercke, R. W. Mayer, R. Schlogl, Kinet. Catal. 2003, 44, 432-440.

[26] P. Christopher, S. Linic, Chem CatChem 2010, 2, 78 -83.

[27] J. Q. Lu, J. J. Bravo-Suarez, A. Takahashi, M. Haruta, S. T. Oyama, J. Catal. 2005, 232, 85-95.
[28] X. L. Jing, J. L. Huang, H. X. Wang, M. M. Du, D. H. Sun, Q. B. Li, Chem. Eng. J. 2016, 284, 149-157.

Received: April 21, 2016

Published online: 


\section{Communications}

Heterogeneous Catalysis

A. Ramirez, J. L. Hueso,* H. Suarez,

R. Mallada, A. Ibarra, S. Irusta,

J. Santamaria** IIII-IIII

A Nanoarchitecture Based on Silver and Copper Oxide with an Exceptional Response in the Chlorine-Promoted Epoxidation of Ethylene

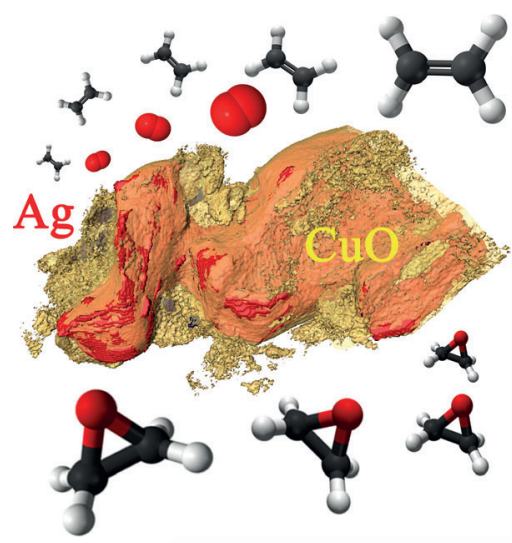

When silver meets copper oxide: A catalyst composed of silver nanostructures dispersed within a nanotubular copper oxide support was found to be an excellent catalyst for the selective epoxidation of ethylene at temperatures below $250^{\circ} \mathrm{C}$ The catalyst can accommodate chlorine promoters in a single pretreatment step with the $\mathrm{CuO}$ acting essentially as a $\mathrm{Cl}$ sponge, thus avoiding, for the most part, irreversible catalyst poisoning.

\section{Heterogene Katalyse}

A. Ramirez, J. L. Hueso,* H. Suarez,

R. Mallada, A. Ibarra, S. Irusta,

J. Santamaria* |III-IIII

A Nanoarchitecture Based on Silver and Copper Oxide with an Exceptional Response in the Chlorine-Promoted Epoxidation of Ethylene

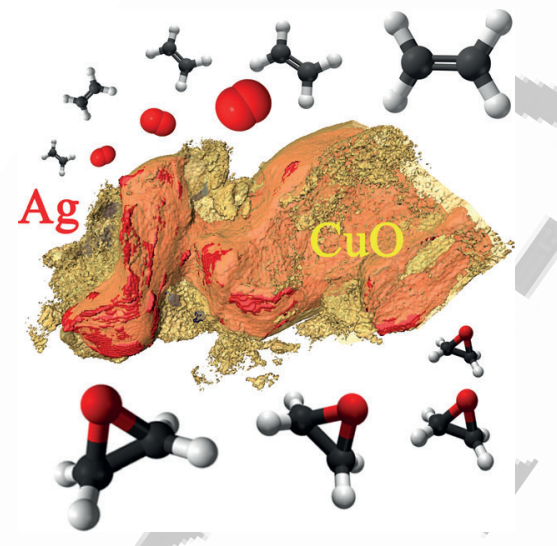

Dispergierte Silber-Nanostrukturen in einem Träger aus Kupferoxid-Nanoröhren katalysieren die selektive Epoxidierung von Ethylen bei Temperaturen unter $250^{\circ} \mathrm{C}$. In einem Vorbehandlungsschritt nimmt der Katalysator Chlor-Promotoren auf, wobei $\mathrm{CuO}$ als $\mathrm{Cl}$-Schwamm fungiert und eine irreversible Vergiftung des Katalysators weitestgehend vermeidet.

Please check that the ORCID identifiers listed below are correct. We encourage all authors to provide an ORCID identifier for each coauthor. ORCID is a registry that provides researchers with a unique digital identifier. Some funding agencies recommend or even require the inclusion of ORCID IDs in all published articles, and authors should consult their funding agency guidelines for details. Registration is easy and free; for further information, see http://orcid.org/.

Adrian Ramirez

Dr. Jose L. Hueso http://orcid.org/0000-0002-4546-4111

Hugo Suarez

Dr. Reyes Mallada

Dr. Alfonso Ibarra

Dr. Silvia Irusta

Prof. Jesus Santamaria 